\title{
BMJ Open Do people with mental health problems have lower adherence to precautionary measures in COVID-19 pandemic? A cross-sectional observational study in Hong Kong
}

\author{
Allen T C Lee (D) , ${ }^{1}$ Gabriel W H Cheng, ${ }^{1}$ Cuichan Lin, ${ }^{1}$ Brian H C Wong, ${ }^{2}$ \\ Linda Chiu Wa Lam ${ }^{1}$
}

To cite: Lee ATC, Cheng GWH, Lin C, et al. Do people with mental health problems have lower adherence to precautionary measures in COVID-19 pandemic? A crosssectional observational study in Hong Kong. BMJ Open 2021;11:e046658. doi:10.1136/ bmjopen-2020-046658

- Prepublication history and additional supplemental material for this paper are available online. To view these files, please visit the journal online (http://dx.doi.org/10.1136/ bmjopen-2020-046658)

Received 05 November 2020 Accepted 04 August 2021

\section{Check for updates}

(c) Author(s) (or their employer(s)) 2021. Re-use permitted under CC BY-NC. No commercial re-use. See rights and permissions. Published by BMJ.

${ }^{1}$ Department of Psychiatry, Faculty of Medicine, The Chinese University of Hong Kong, Hong Kong, SAR, People's Republic of China

${ }^{2}$ Department of Psychiatry, Tai Po Hospital, Hong Kong, SAR, People's Republic of China

Correspondence to

Professor Linda Chiu Wa Lam; cwlam@cuhk.edu.hk

\section{ABSTRACT}

Objectives Mental health problems are prevalent during the COVID-19 pandemic, but their effect on adherence to precautionary measures is not well understood. Given that psychological morbidities are associated with lower treatment adherence, and that precautionary measures are important in containing the spread of COVID-19, this study aims to determine if people with mental health problems have lower adherence to precautionary measures against COVID-19.

Design We conducted a cross-sectional territory-wide online survey between 17 June and 31 July 2020 during the COVID-19 pandemic. Clinically significant mental health problems, adherence to precautionary behaviours, and confounding factors such as sociodemographic factors and self-reported physical health were assessed.

Setting The link to the questionnaire was disseminated to the general population in all 18 districts of Hong Kong using various social media platforms.

Participants 1036 individuals completed the survey. Of them, 1030 met the inclusion criteria of being adult Hong Kong residents.

Primary outcome Adherence to precautionary measures against COVID-19, including wearing face mask, frequent handwashing, household disinfection, social distancing, minimising unnecessary travel, and stocking up on food and daily essentials.

Results Of the 1030 participants, 166 (16.1\%)

had clinically significant mental health problems. Interestingly, they were more likely to stock up on food and daily essentials during the pandemic $(7$ (4.2\%) vs $15(1.7 \%), p=0.04$; unadjusted $\mathrm{OR}=2.49,95 \% \mathrm{Cl}=1.00$ to $6.21, p<0.05$ ) and had a lesser tendency to stop social distancing even if the pandemic subsides (86 $(51.8 \%)$ vs $513(59.4 \%), p=0.07$; unadjusted $\mathrm{OR}=0.74$, $95 \% \mathrm{Cl}=0.53$ to $1.03, \mathrm{p}=0.07)$. The latter association remained significant after adjusting for the confounding factors (adjusted $\mathrm{OR}=0.68,95 \% \mathrm{Cl}=0.48$ to 0.96 , $p=0.03$ ).

Conclusions Contrary to our hypothesis, people who are mentally unwell might go beyond the recommended precautionary measures. Our findings highlight the need to identify mental health problems and provide care and

\section{Strengths and limitations of this study}

- An original large territory-wide population-based study to identify the association between mental health and behavioural responses to COVID-19.

- Validated assessment of clinically significant mental health problems.

- Broad assessment of adherence to precautionary measures against COVID-19.

- Inferring a causal relationship between mental disorder and adherence to precautionary measures against COVID-10 requires care because of the cross-sectional observational nature of the study design.

- The study sample was limited to the Hong Kong residents only and might have missed those not competent in information technology.

support for those who might go too far with precautionary measures.

Trial registration number ChiCTR 2000033936.

\section{INTRODUCTION}

The COVID-19 pandemic is a major public health concern worldwide, resulting in high prevalence of depression, anxiety and stress in the general populations across countries. $^{1-4}$ The impact of COVID-19 pandemic on mental health in low/middle-income countries (LMICs), including those in South Asia countries, is particularly concerning. ${ }^{5-8}$

While precautionary measures such as wearing face mask have increasingly been shown to be effective and crucial in controlling the spreading of COVID-19, ${ }^{9}{ }^{10}$ growing evidence suggests that some measures such as social distancing are associated with higher risks of social isolation, loneliness, and poorer physical and mental health. ${ }^{112}$ On the other hand, whether mental health 
problems are associated with poorer adherence to these precautionary measures against COVID-19 is not fully understood. Previous literature has consistently demonstrated that people with psychological morbidities such as depression are at greater risk of having lower adherence to medical treatment and healthy lifestyle practice. ${ }^{13} 14$ Not only do they have poorer control of hypertension and diabetes, ${ }^{15-17}$ but they are also more likely to have worsen outcomes in cardiovascular diseases and stroke ${ }^{1819}$ and higher mortality rate. ${ }^{20-22}$ With the success of mitigating the spread of COVID-19 infection highly depending on the community's adherence to precautionary measures, ${ }^{23} 24$ it would be of great clinical and public health interest to examine if people with mental health problems are associated with lower adherence to precautionary measures, including social distancing, while taking into consideration the potential confounding effect of various social determinants of mental health changes in the COVID-19 pandemic, such as young and middle-aged adults, female, lower socioeconomic status and subjective poorer physical health. ${ }^{25-27}$

In this study, we conducted an online survey to address the knowledge gap of mental health associating with adherence to precautionary behaviours against COVID-19 in the general population. The objectives were to examine the adherence to different precautionary measures against COVID-19 during the pandemic and to test if the response to adherence differed between people with and without mental health problems. We hypothesised that people with mental health problems had lower adherence to precautionary measures. Our findings might provide evidence that mental health plays a major role in adherence to public health measures in minimising the risk of contracting and spreading COVID-19, and highlight the importance of identifying and treating psychological morbidities in enhancing the community's effort of fighting against COVID-19.

\section{METHODS}

\section{Study setting, design and participants}

This was a cross-sectional territory-wide online survey conducted in Hong Kong between 17 June and 31 July 2020 during which Hong Kong was experiencing the second wave of the COVID-19 pandemic. The survey was disseminated using the university mass email system and various social media platforms (including Facebook, WhatsApp and WeChat) to the general population and the community cohorts from our ongoing governmentcommissioned studies, where the households were randomly selected based on the addresses from all 18 districts of Hong Kong generated from the Census and Statistics Department of the Government of Hong Kong. Inclusion criteria were Hong Kong residents aged 18 years or older with internet access. Those who were younger than age 18 years, non-local residents, and having impairments in communication or understanding instructions were excluded. The whole survey took about $5 \mathrm{~min}$ to complete, and participants only needed to choose the answers that best reflected their view. A soft copy of the questionnaire used in our survey can be found in the online supplemental file 1. Participants were free to participate or withdraw anytime from this survey; those who did not complete or submit their responses online would not have any negative consequences. As there was no direct contact with participant or data collection of personal identifier, informal consent was sought from participants (ie, those who successfully completed and submitted their answers online were considered as giving their implied consent).

\section{Assessment of mental health problems}

The 6-item Kessler scale (K6), a simple and quick selfadministered rating scale developed to assess psychological distress and screen for cases of clinically significant mental health problems including but not limiting to major depressive disorder and anxiety disorder, was used in this study. ${ }^{28}$ It has already been validated locally, with good psychometric properties reported. ${ }^{29}$ Participants were asked to rate how often they felt (1) nervous, (2) hopeless, (3) restless or fidgety, (4) so depressed that nothing could cheer them up, (5) that everything was an effort, and (6) worthless in the past 30 days. With each item coding from 0 to 4 , K6 score ranges from 0 to 24 . Higher scores represent greater severity. A cut-off of 13 or above is defined as having clinically significant mental health problems. ${ }^{29}$

\section{Assessment of adherence to precautionary measures}

As the general population in Hong Kong had a remarkably high adherence rate to precautionary measures against COVID-19, with $97 \%$ reported wearing face masks, ${ }^{24}$ we assessed the minimal precautionary behaviour that the participants would maintain if the pandemic continued for another 6 months, as well as the first precautionary measure that they would discontinue if the pandemic subsided in 3 months. In this survey, participants were asked to choose two behaviours that they would most likely continue or discontinue. Examples of precautionary behaviours commonly adopted by the local population included wearing face mask, frequent handwashing, household disinfection, social distancing, avoiding unnecessary travel, and stocking up on food and daily essentials.

\section{Assessment of covariates}

Potential confounding factors including basic sociodemographics (age, sex, educational level and employment status), self-reported physical health status (assessed by the 5-point Likert scale of self-rated health assessment used in the World Health Survey, ${ }^{30}$ with the possible choices being 'very good', 'good', 'moderate', 'bad' or 'very bad'), and previous personal or close encounter with severe acute respiratory syndrome (SARS) in 2003 or COVID-19 (participants, their family members, or people 
with whom they had close contact diagnosed with SARS or COVID-19 before) were examined.

\section{Sample size estimation}

Sample size estimation was performed using $G^{*}$ Power V.3.1. Based on previous literature on the effect of depression on non-compliance with medical treatment, ${ }^{13}$ adherence rate of precautionary measures against COVID-19 in the local general population ${ }^{31}$ and prevalence of common mental health disorders in Hong Kong, ${ }^{32}$ we estimated that a sample size of 200 participants would yield enough power to detect a significant difference in the response towards precautionary measures between those with and without mental health problems (alpha $=0.05$, power $=80 \%$ ). Taking into consideration of the need for allowing multiple comparisons and the potential confounding effects on adherence to infection control measures, in which $40 \%$ of the variance might be due to confounders, a sample of 1000 participants would be sufficiently large in detecting significant differences in precautionary behaviours between the two groups.

\section{Statistical analysis}

Statistical analysis was performed using the IBM SPSS Statistics, V.26.0 (IBM Corp). Comparison of variables between participants with and without mental health problems was analysed by the independent t-test or the $\chi^{2}$ test, as appropriate. The level of statistical significance was set at $\mathrm{p}<0.05$ (two-tailed). We analysed self-rated physical health as a dichotomous measure, with 'bad' and 'very bad' as poor. Logistic regression analysis was performed to examine the association between clinically significant mental health problems and responses to precautionary measures, with the former treated as independent variable and the latter as dependent variable. Model 1 was unadjusted, whereas model 2 was adjusted for potential confounding factors including age, sex, educational level, employment status, physical health, and previous encounter with SARS or COVID-19. The ORs were computed to yield point estimates with $95 \%$ CIs.

\section{Patient and public involvement}

None involved.

\section{RESULTS}

\section{Prevalence and characteristics of participants with mental health problems}

A total of 1036 individuals responded to our online survey. Of these, six were excluded because they did not meet our inclusion criteria. Hence, 1030 participants were included into this study. The mean K6 score of our cohort was $7.7(\mathrm{SD}=4.7)$. A total of $166(16.1 \%)$ participants scored above the cut-off for clinically significant mental health problems. They were younger, with higher educational level and poorer self-rated physical health, than those without mental health problems (table 1). There was no significant difference in sex, unemployment rate, or previous encounter with SARS or COVID-19 between the two groups.

\section{Precautionary behaviours and their differences in adherence} between those with and without mental health problems

Majority of participants reported that they would maintain wearing face masks $(n=980 ; 95.1 \%)$, followed by frequent handwashing $(\mathrm{n}=723 ; 70.2 \%)$, social distancing $(\mathrm{n}=123 ; 11.9 \%)$, household disinfection $(\mathrm{n}=116 ; 11.3 \%)$, avoiding unnecessary travel $(\mathrm{n}=93 ; 9.3 \%)$, and stocking up on food and daily essentials $(\mathrm{n}=22 ; 2.1 \%)$, as the COVID-19 pandemic persisted. While the proportion of those maintaining the use of face mask, frequent handwashing, social distancing, household disinfection and avoiding unnecessary travel were similar between the two groups (table 2), those with mental health problems had higher prevalence of stocking up on food and daily essentials than those without ( $4.2 \%$ vs $1.7 \%, \mathrm{p}=0.04$ ).

Majority of participants reported that they would discontinue social distancing first $(\mathrm{n}=599,58.2 \%)$, followed by stocking up on food and daily essentials $(\mathrm{n}=560,54.4 \%)$, avoiding unnecessary travel $(\mathrm{n}=428,41.6 \%)$, household disinfection $(\mathrm{n}=202,19.6 \%)$, wearing face mask $(\mathrm{n}=181$, $17.6 \%)$ and lastly frequent handwashing $(\mathrm{n}=90,8.7 \%)$, when the pandemic subsided. However, those with mental health problems had a lesser tendency to stop practising social distancing ( $51.8 \%$ vs $59.4 \%, \mathrm{p}=0.07)$ and were more likely to stop stocking up on food and daily essentials $(65.1 \%$ vs $52.3 \%, \mathrm{p}=0.003)$ than people who

Table 1 Comparison of characteristics between participants with and without clinically significant mental health problems

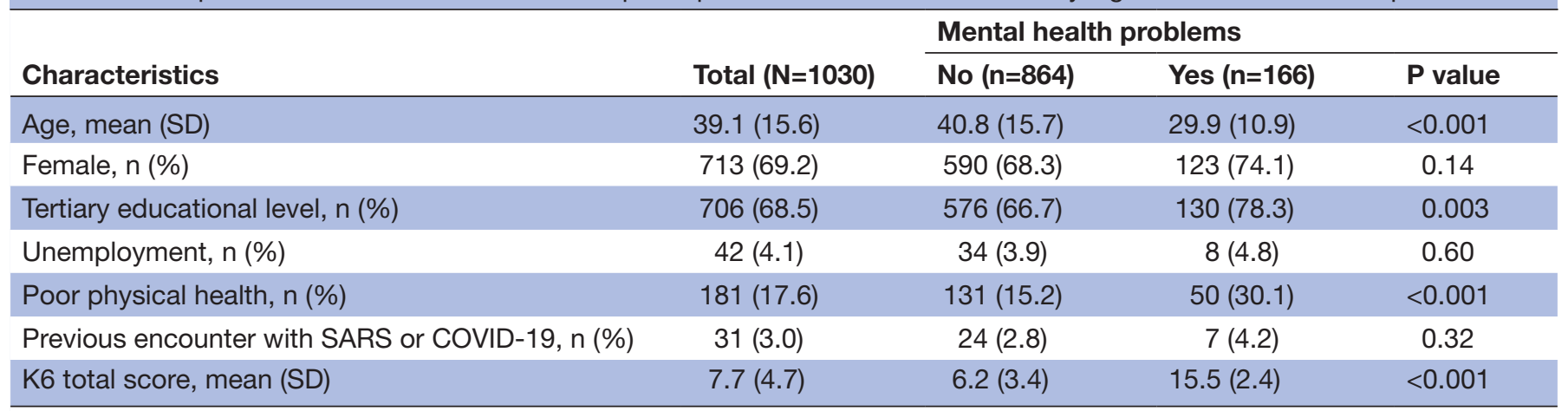

K6, 6-item Kessler scale; SARS, severe acute respiratory syndrome. 
Table 2 Differences in precautionary behaviours to be maintained when the COVID-19 pandemic persisted between participants with and without mental health problems

\begin{tabular}{lllll}
\hline & & \multicolumn{2}{l}{ Mental health problems } \\
\cline { 3 - 5 } Precautionary measures & Total $(\mathbf{N}=\mathbf{1 0 3 0})$ & No $(\mathbf{n}=\mathbf{8 6 4})$ & Yes $(\mathbf{n}=\mathbf{1 6 6})$ & P value \\
\hline Wearing face mask, $\mathrm{n}(\%)$ & $980(95.1)$ & $823(95.3)$ & $157(94.6)$ & 0.71 \\
Frequent handwashing, $\mathrm{n}(\%)$ & $723(70.2)$ & $613(70.9)$ & $110(66.3)$ & 0.23 \\
Social distancing, $\mathrm{n}(\%)$ & $123(11.9)$ & $100(11.6)$ & $23(13.9)$ & 0.41 \\
Household disinfection, $\mathrm{n}(\%)$ & $116(11.3)$ & $94(10.9)$ & $22(13.3)$ & 0.38 \\
Avoiding unnecessary travel, $\mathrm{n}(\%)$ & $93(9.3)$ & $82(9.5)$ & $11(6.6)$ & 0.24 \\
Stocking up on food and daily essentials, $\mathrm{n}(\%)$ & $22(2.1)$ & $15(1.7)$ & $7(4.2)$ & 0.04 \\
\hline
\end{tabular}

were mentally well (table 3 ). No significant difference was found in the preference of discontinuing other precautionary behaviours when the pandemic subsided between those with and without mental health problems (table 3).

\section{Associations of mental health and other factors with} responses to continuation of precautionary measures when the pandemic persisted

The ORs of clinically significant mental health problems and other potential confounding factors (age, sex, educational level, employment status, poor physical health, and previous encounter with SARS or COVID-19) for maintaining different types of precautionary behaviours while the pandemic persisted were described in online supplemental tables $1-6$.

The OR for maintenance of stocking up on food and daily essentials in participants with mental health problems was 2.49 (95\% CI $=1.00$ to $6.21, \mathrm{p}<0.05$, model 1 in table 4). After adjusting for age, sex, educational level, employment status, physical health, and previous encounter with SARS or COVID-19, the OR was $1.99(95 \%$ $\mathrm{CI}=0.74$ to $5.33, \mathrm{p}=0.17$, model 2 in table 4 ). The attenuation of OR appears to be driven by previous encounter with SARS or COVID-19 (OR=5.76, 95\% CI=1.53 to 21.70, $\mathrm{p}=0.01$ ) and unemployment, with all participants who were unemployed $(n=42)$ reporting that they would not maintain stocking up on food and daily essentials if the pandemic continued to persist (online supplemental table 6).
Associations of mental health and other factors with responses to discontinuation of precautionary measures when the pandemic subsided

The ORs of clinically significant mental health problems and other potential confounding factors for discontinuing various types of precautionary behaviours when the pandemic subsided were described in online supplemental tables 7-12.

The OR for discontinuing social distancing in participants with mental health problems when the pandemic subsided was $0.74(95 \% \mathrm{CI}=0.53$ to $1.03, \mathrm{p}=0.07$, model 1 in table 5). The OR remained low $(\mathrm{OR}=0.68,95 \% \mathrm{CI}=0.48$ to $0.96, p=0.03$ ), even when adjusting for age, sex, educational level, employment status, physical health, and previous encounter with SARS or COVID-19 (model 2 in table 5).

The OR for discontinuing stocking up on food and daily essentials in those with mental health problems when the pandemic subsided was $1.70(95 \% \mathrm{CI}=1.20$ to 2.40, $\mathrm{p}=0.003$, model 1 in table 5 ). After adjusting for the potential confounding factors, the OR was $1.09(95 \%$ $\mathrm{CI}=0.75$ to $1.58, \mathrm{p}=0.66$, model 2 in table 5 ).

\section{DISCUSSION}

Contrary to our hypothesis of people with mental health problems having lower adherence to precautionary measures against COVID-19, our study suggests that they might practise these to a greater and longer

Table 3 Differences in precautionary behaviours to be discontinued when the COVID-19 pandemic subsided between participants with and without mental health problems

\begin{tabular}{|c|c|c|c|c|}
\hline \multirow[b]{2}{*}{ Precautionary measures } & \multirow[b]{2}{*}{ Total $(\mathrm{N}=1030)$} & \multicolumn{3}{|c|}{ Mental health problems } \\
\hline & & No $(n=864)$ & Yes $(n=166)$ & $P$ value \\
\hline Social distancing, n (\%) & $599(58.2)$ & $513(59.4)$ & $86(51.8)$ & 0.07 \\
\hline Avoiding unnecessary travel, n (\%) & $428(41.6)$ & $358(41.4)$ & $70(42.2)$ & 0.86 \\
\hline Household disinfection, n (\%) & $202(19.6)$ & $175(20.3)$ & 27 (16.3) & 0.24 \\
\hline Frequent handwashing, n (\%) & $90(8.7)$ & $74(8.6)$ & $16(9.6)$ & 0.65 \\
\hline
\end{tabular}

\section{Mental health problems}


Table 4 Summary of estimated ORs and 95\% Cls for maintenance of different types of precautionary behaviours in people with clinically significant mental health problems when the pandemic persisted

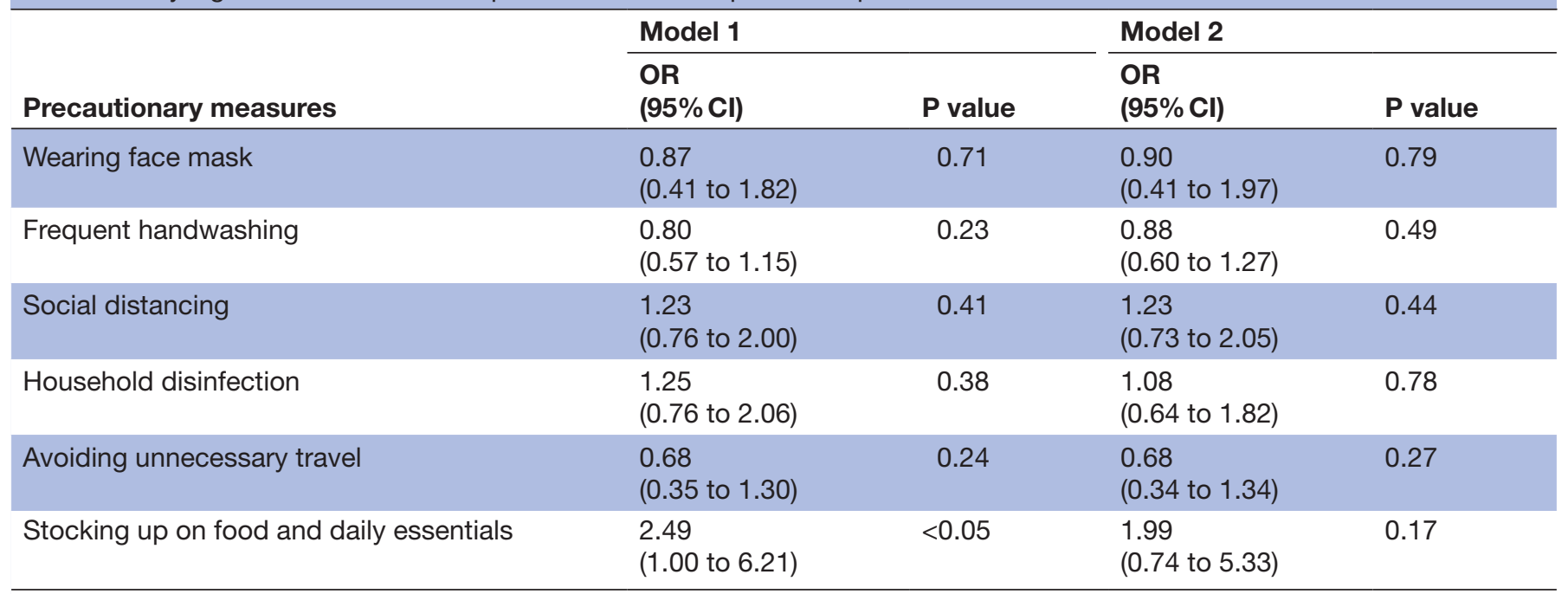

Model 1: unadjusted.

Model 2: adjusted for age, sex, educational level, employment status, physical health, and previous encounter with SARS or COVID-19.

SARS, severe acute respiratory syndrome.

extent, as evidenced by our findings of them having a higher tendency of stocking up on food and daily essentials while the pandemic persists, and being more likely to continue practising social distancing even when the pandemic subsides. More importantly, the latter association remained robust after controlling for potential confounding factors including age, sex, educational level, employment status, physical health, and previous encounter with SARS or COVID-19. From a clinical and public health perspective, our findings highlight the importance of screening mental health problems among those who might be going too far with the safety measures, and the need to provide mental healthcare and support for these individuals.

Previous studies have consistently demonstrated that people with mental disorders have lower adherence to medical treatment and healthy lifestyle practice. ${ }^{13} 14$ However, in this study, we did not find an association between psychological morbidities and lower adherence to precautionary measures against COVID19. Instead, our findings suggest that people who are mentally unwell might go beyond the recommended measures. Our observation is consistent with the findings of a recent study by Carlucci $e t a l^{33}$ which shows that

Table 5 Summary of estimated ORs and 95\% Cls for discontinuation of different types of precautionary behaviours in people with clinically significant mental health problems when the pandemic subsided

\begin{tabular}{|c|c|c|c|c|}
\hline \multirow[b]{2}{*}{ Precautionary measures } & \multicolumn{2}{|l|}{ Model 1} & \multicolumn{2}{|l|}{ Model 2} \\
\hline & $\begin{array}{l}\text { OR } \\
(95 \% \mathrm{Cl})\end{array}$ & $P$ value & $\begin{array}{l}\text { OR } \\
(95 \% \mathrm{Cl})\end{array}$ & P value \\
\hline Stocking up on food and daily essentials & $\begin{array}{l}1.70 \\
(1.20 \text { to } 2.40)\end{array}$ & 0.003 & $\begin{array}{l}1.09 \\
(0.75 \text { to } 1.58)\end{array}$ & 0.66 \\
\hline Household disinfection & $\begin{array}{l}0.77 \\
(0.49 \text { to } 1.19)\end{array}$ & 0.24 & $\begin{array}{l}0.86 \\
(0.54 \text { to } 1.37)\end{array}$ & 0.51 \\
\hline Wearing face mask & $\begin{array}{l}0.81 \\
(0.51 \text { to } 1.27)\end{array}$ & 0.35 & $\begin{array}{l}1.34 \\
(0.82 \text { to } 2.20)\end{array}$ & 0.25 \\
\hline
\end{tabular}

Model 1: unadjusted.

Model 2: adjusted for age, sex, educational level, employment status, physical health, and previous encounter with SARS or COVID-19.

SARS, severe acute respiratory syndrome. 
people with anxiety appear to be more likely to comply with quarantine guidelines. While our findings show that their behaviours did not appear to be completely irrational because they were at least as prepared as those who were mentally well to stop stocking up on food and daily essentials when the pandemic subsided, their extended practice of social distancing could potentially lead to functional impairment, poorer quality of life and further worsening of mental health, especially since social isolation and loneliness are strongly associated with various negative health consequences, both physically and psychologically. ${ }^{34}$ Although we did not investigate the underlying mechanisms of the observed association, we speculate that these individuals have higher level of fear towards COVID-19, greater uncertainty about the future and lower level of perceived control. Previous literature supports that there are circumstances when people with depression might be less willing to take risks, as determined by their level of trust, confidence in future and perceived locus of control. ${ }^{35}$ These are in line with our present observation and might explain some of the excessive dysfunctional precautionary behaviours reported in the general population during the COVID-19 pandemic.

Mounting evidence shows that the prevalence of mental health problems increases substantially during the COVID-19 pandemic, ${ }^{1-4}$ and that people living in LMICs or places where health inequality is evident might be even more susceptible to mental health changes. ${ }^{5-8}$ In the present study, we found that people with mental health problems had a greater tendency to stock up food and daily essentials than those without. Although the OR was no longer significant after adjusting for other confounding factors, we noticed that all the participants who were unemployed reported that they would not maintain stocking up on food and daily essentials should the pandemic continue to persist. Although we did not have the opportunity to explore the underlying reason, we speculate that they chose not to continue stockpiling food and daily supplies largely because they were financially unable to do so. Therefore, care needs to be taken when interpreting this negative result, and it would be important to further examine not only the prevalence of mental health problems in LMICs and places with health inequalities but more importantly how their people, especially those with mental illness, cope with the COVID-19 pandemic in the face of various limitations and challenges.

Our present findings support and add to the existing literature that psychological morbidities might be present in those who practise much precautionary measures. From a clinical perspective, healthcare professionals need to be mindful of those with disproportionate precautionary behaviours potentially having mental health problems and be prepared in providing mental healthcare and support for these individuals. Early identification of mental health problems and timely intervention using novel strategies such as online resources and telecare would be important in improving resilience, reducing morbidities, and minimising maladaptive coping behaviours such as panic buying and excessive self-isolation during the pandemic. ${ }^{36}$ Also, from a public health perspective, implementing comprehensive government policies in preventing and controlling the spread of the virus while proactively addressing the socioeconomic challenges arising from the pandemic, together with timely dissemination of the latest evidence-based health advice in response to the constantly changing situation of the pandemic to address the fear and uncertainties of COVID-19 infection, would be crucial for promoting effective community responses to COVID-19 and increasing the success of the general public in empowering themselves and enhancing coping strategies through this unprecedented crisis.

This study had several strengths. To our knowledge, this is the first territory-wide population-based study to identify the association between mental health and behavioural responses to COVID-19. Validated assessment tool was used to assess clinically significant mental health problems in the general population, and adherence to a wide variety of precautionary measures against COVID-19 was examined. Various important potential confounding factors ranging from physical health to sociodemographic factors were included in this study. Also, the Likert scales used in the assessment were balanced and symmetric. Additionally, the online questionnaire was designed such that participants had to complete all the answers before they could submit their responses, and their choices for the top two precautionary measures most likely continued or discontinued could not be duplicated.

Nevertheless, this study had a number of limitations. First, given the cross-sectional observational nature of the study design, caution requires when inferring a causal relationship between mental disorders and precautionary measures against COVID-19. Second, the study sample was limited to Hong Kong residents only and might have missed those not competent in information technology. Given that the COVID-19 situation and the acceptance rate to precautionary measures varied among places and subgroups, care needs to be taken when applying our findings to the other communities or populations. Third, this study was conducted when Hong Kong was experiencing the second wave of COVID-19 infection. While our data reflected the responses to precautionary measures during the critical period of COVID-19 pandemic when the number of infected cases surged, the responses might be different from those in the earlier stage of the pandemic. Fourth, mental and physical health were self-rated, and assessments of precautionary behaviours were based on closed-ended questions. Health records were not reviewed, so the diagnosis, onset, duration and treatment of mental health problems could not be ascertained. Objective data on adherence rate of infection control measures were not available. In Hong Kong, all confirmed COVID-19 cases are by law compulsorily admitted to negative-pressure isolation rooms in public hospitals, and all suspected COVID-19 cases or individuals who have contact with COVID-19 cases 
are compulsorily admitted to quarantine centres. With voluntary home quarantine not allowed, reviewing the proportion of people arrested or sanctioned following non-compliance to home quarantine as an objective measure of degree of adherence is therefore not applicable to Hong Kong. Nevertheless, recall bias was unlikely because this study was conducted when the pandemic was still ongoing. Last, while the inclusion and exclusion criteria of this online study were minimal, sampling and response biases could not be completely excluded.

In conclusion, our findings suggest that people with clinically significant mental health problems might practise precautionary measures to COVID-19 to a greater and longer extent than those without. Future trials to identify treatment of mental health problems in modifying precautionary behaviours such that sensible infection control measures are implemented will provide additional insight to the causality between the two and highlight its clinical significance in improving the mental health, functioning and quality of life during the pandemic.

Acknowledgements We thank all the participants for their time to be involved in this study.

Contributors ATCL and LCWL conceived of and designed the study. ATCL, GWHC, $\mathrm{CL}$ and BHCW searched the literature, collected and analysed the data. ATCL interpreted the data and wrote the paper. GWHC, CL, BHCW and LCWL critically edited and revised the work. LCWL supervised the study, has full access to all the data in the study and has the final responsibility for the decision to submit for publication. All authors read and approved the final manuscript.

Funding The authors have not declared a specific grant for this research from any funding agency in the public, commercial or not-for-profit sectors.

Competing interests None declared.

Patient consent for publication Not required.

Ethics approval This study was approved by the Survey and Behavioural Research Ethics Committee (SBREC) of the Faculty of Medicine of the Chinese University of Hong Kong (reference number: SBRE-19-713) and was performed in accordance with the ethical standards laid down in the 1964 Declaration of Helsinki and its later amendments.

Provenance and peer review Not commissioned; externally peer reviewed.

Data availability statement Data are available upon reasonable request. The data that support the findings of this study are available from the corresponding author Linda LAM upon reasonable request.

Supplemental material This content has been supplied by the author(s). It has not been vetted by BMJ Publishing Group Limited (BMJ) and may not have been peer-reviewed. Any opinions or recommendations discussed are solely those of the author(s) and are not endorsed by BMJ. BMJ disclaims all liability and responsibility arising from any reliance placed on the content. Where the content includes any translated material, BMJ does not warrant the accuracy and reliability of the translations (including but not limited to local regulations, clinical guidelines, terminology, drug names and drug dosages), and is not responsible for any error and/or omissions arising from translation and adaptation or otherwise.

Open access This is an open access article distributed in accordance with the Creative Commons Attribution Non Commercial (CC BY-NC 4.0) license, which permits others to distribute, remix, adapt, build upon this work non-commercially, and license their derivative works on different terms, provided the original work is properly cited, appropriate credit is given, any changes made indicated, and the use is non-commercial. See: http://creativecommons.org/licenses/by-nc/4.0/.

\section{ORCID iD}

Allen T C Lee http://orcid.org/0000-0003-4196-5442
REFERENCES

1 Salari N, Hosseinian-Far A, Jalali R, et al. Prevalence of stress, anxiety, depression among the general population during the COVID-19 pandemic: a systematic review and meta-analysis. Global Health 2020;16:57.

2 Luo M, Guo L, Yu M, et al. The psychological and mental impact of coronavirus disease 2019 (COVID-19) on medical staff and general public - a systematic review and meta-analysis. Psychiatry Res 2020;291:113190.

3 Vindegaard N, Benros ME. COVID-19 pandemic and mental health consequences: systematic review of the current evidence. Brain Behav Immun 2020;89:531-42.

4 Balsamo M, Carlucci L. Italians on the age of COVID-19: the selfreported depressive symptoms through web-based survey. Front Psychol 2020;11:569276.

5 Kola L, Kohrt BA, Hanlon C, et al. COVID-19 mental health impact and responses in low-income and middle-income countries: reimagining global mental health. Lancet Psychiatry 2021;8:535-50.

6 Das R, Hasan MR, Daria S, et al. Impact of COVID-19 pandemic on mental health among General Bangladeshi population: a crosssectional study. BMJ Open 2021;11:e045727.

7 Repon MAU, Pakhe SA, Quaiyum S, et al. Effect of COVID-19 pandemic on mental health among Bangladeshi healthcare professionals: a cross-sectional study. Sci Prog 2021;104:368504211026409.

8 Hossain MM, Rahman M, Trisha NF, et al. Prevalence of anxiety and depression in South Asia during COVID-19: a systematic review and meta-analysis. Heliyon2021;7:e06677.

9 Chu DK, Akl EA, Duda S, et al. Physical distancing, face masks, and eye protection to prevent person-to-person transmission of SARS-CoV-2 and COVID-19: a systematic review and meta-analysis. Lancet 2020;395:1973-87.

10 Rader B, White LF, Burns MR, et al. Mask-wearing and control of SARS-CoV-2 transmission in the USA: a cross-sectional study. Lancet Digit Health 2021;3:e148-57.

11 Morina N, Kip A, Hoppen TH, et al. Potential impact of physical distancing on physical and mental health: a rapid narrative umbrella review of meta-analyses on the link between social connection and health. BMJ Open 2021;11:e042335.

12 Castaldelli-Maia JM, Marziali ME, Lu Z, et al. Investigating the effect of national government physical distancing measures on depression and anxiety during the COVID-19 pandemic through meta-analysis and meta-regression. Psychol Med 2021;51:881-93.

13 DiMatteo MR, Lepper HS, Croghan TW. Depression is a risk factor for noncompliance with medical treatment: meta-analysis of the effects of anxiety and depression on patient adherence. Arch Intern Med 2000;160:2101-7.

14 Ciechanowski PS, Katon WJ, Russo JE. Depression and diabetes: impact of depressive symptoms on adherence, function, and costs. Arch Intern Med 2000;160:3278-85.

15 Lustman PJ, Anderson RJ, Freedland KE, et al. Depression and poor glycemic control: a meta-analytic review of the literature. Diabetes Care 2000;23:934-42.

16 Nouwen A, Adriaanse MC, van Dam K, et al. Longitudinal associations between depression and diabetes complications: a systematic review and meta-analysis. Diabet Med 2019;36:1562-72.

17 Meng L, Chen D, Yang Y, et al. Depression increases the risk of hypertension incidence: a meta-analysis of prospective cohort studies. J Hypertens 2012;30:842-51.

18 Gan Y, Gong Y, Tong X, et al. Depression and the risk of coronary heart disease: a meta-analysis of prospective cohort studies. BMC Psychiatry 2014;14:371.

19 Ayerbe L, Ayis S, Wolfe CDA, et al. Natural history, predictors and outcomes of depression after stroke: systematic review and metaanalysis. Br J Psychiatry 2013;202:14-21.

20 van Dooren FEP, Nefs G, Schram MT, et al. Depression and risk of mortality in people with diabetes mellitus: a systematic review and meta-analysis. PLoS One 2013;8:e57058.

21 Frasure-Smith N, Lespérance F, Talajic M. Depression following myocardial infarction. Impact on 6-month survival. JAMA 1993;270:1819-25.

22 Jiang W, Alexander J, Christopher E, et al. Relationship of depression to increased risk of mortality and rehospitalization in patients with congestive heart failure. Arch Intern Med 2001;161:1849-56.

23 Howard J, Huang A, Li Z, et al. An evidence review of face masks against COVID-19. Proc Natl Acad Sci U S A 2021;118:e2014564118.

24 Cheng VC-C, Wong S-C, Chuang VW-M, et al. The role of community-wide wearing of face mask for control of coronavirus disease 2019 (COVID-19) epidemic due to SARS-CoV-2. Journal of Infection 2020;81:107-14. 
25 Hubbard G, den Daas C, Johnston M, et al. Sociodemographic and psychological risk factors for anxiety and depression: findings from the COVID-19 health and adherence research in Scotland on mental health (CHARIS-MH) cross-sectional survey. Int J Behav Med 2021;3:1-13.

26 Bernardini F, Attademo L, Rotter M, et al. Social determinants of mental health as mediators and moderators of the mental health impacts of the COVID-19 pandemic. PS 2021;72:598-601.

27 Campo-Arias A, De Mendieta CT. Social determinants of mental health and the COVID-19 pandemic in low-income and middleincome countries. Lancet Glob Health 2021;9:e1029-30.

28 Kessler RC, Barker PR, Colpe LJ, et al. Screening for serious mental illness in the general population. Arch Gen Psychiatry 2003;60:184-9.

29 Lee S, Tsang A, Ng KL, et al. Performance of the 6-item Kessler scale for measuring serious mental illness in Hong Kong. Compr Psychiatry 2012;53:584-92.

30 Subramanian SV, Huijts T, Avendano M. Self-Reported health assessments in the 2002 World health survey: how do they correlate with education? Bull World Health Organ 2010;88:131-8.
31 Kwok KO, Li KK, Chan $\mathrm{HHH}$, et al. Community responses during early phase of COVID-19 epidemic, Hong Kong. Emerg Infect Dis 2020;26:1575-9.

32 Lam LC-W, Wong CS-M, Wang M-J, et al. Prevalence, psychosocial correlates and service utilization of depressive and anxiety disorders in Hong Kong: the Hong Kong mental morbidity survey (HKMMS). Soc Psychiatry Psychiatr Epidemiol 2015;50:1379-88.

33 Carlucci L, D'Ambrosio I, Balsamo M. Demographic and attitudinal factors of adherence to quarantine guidelines during COVID-19: the Italian model. Front Psychol 2020;11:559288.

34 Leigh-Hunt N, Bagguley D, Bash K, et al. An overview of systematic reviews on the public health consequences of social isolation and loneliness. Public Health 2017;152:157-71.

35 Cobb-Clark DA, Dahmann SC, Kettlewell N. Depression, risk preferences and risk-taking behavior. J Hum Resour 2020:0419-10183R1.

36 Smith AC, Thomas E, Snoswell CL, et al. Telehealth for global emergencies: implications for coronavirus disease 2019 (COVID-19). J Telemed Telecare 2020;26:309-13. 